\title{
La violencia positiva y el imperativo neoliberal de rendimiento en La habitación oscura, de Isaac Rosa
}

\author{
Laura Mercedes Prada*
}

\section{Resumen}

La habitación oscura (2013) de Isaac Rosa advierte, a través de técnicas discursivas como las analepsis y las prolepsis, enumeraciones ascendentes, préstamos de técnicas cinematográficas, entre otras, que la libertad prometida por el sistema neoliberal es una ilusión que tiene como objetivo crear en el individuo la idea de independencia laboral cuando en realidad inocula en él la necesidad de producir constantemente, cumplir con las exigencias autoimpuestas y, de este modo, mantener su estatus o ascender a otro. La autoexplotación de los protagonistas de la novela es una de las representaciones de la violencia positiva, la cual es imperceptible y, por ello, más nociva y peligrosa debido a que los sujetos no se percatan del daño autoinflingido hasta que es demasiado tarde. En este sentido, el cuarto oscuro que un grupo de amigos comparten durante quince años se transforma en el espacio para alejarse del vértigo, el bullicio y las obligaciones que trasfiguran a la persona en prisionera de sus propios mandatos y las demandas implícitas del sistema neoliberal.

Palabras clave: violencia positiva, imperativo neoliberal de rendimiento, libertad, autoexigencia

\section{Positive Violence and the Neoliberal Imperative of Performance in Isaac Rosa's The Dark Room}

\begin{abstract}
The Dark Room (2013) by Isaac Rosa warns, through discursive techniques such as analepsis and prolepsis, ascending enumerations, borrowing from cinematographic techniques, among others, that the freedom promised by the neoliberal system is an illusion that aims to create in the individual the idea of labor independence when in fact it inoculates in them the need to constantly produce, meet self-imposed demands and, in this way, maintain their status or advance to another. The self-exploitation of the protagonists of the novel is one of the representations of positive violence, which is imperceptible and, therefore, more harmful and dangerous because the subjects do not realize the self-inflicted damage until it is too late. In this sense, the dark room that a group of friends share for fifteen years is transformed into the
\end{abstract}

\footnotetext{
${ }^{*}$ Licenciada en Letras Modernas, Profesora Asistente Interina de Literatura Española II, Facultad de Filosofía y Humanidades, Universidad Nacional de Córdoba, Argentina. Miembro del Equipo de Investigación Literatura y biopolítica: retóricas contemporáneas de la violencia, a cargo de la Doctora Graciela Ferrero, Facultad de Lenguas, Universidad Nacional de Córdoba. lauraprada248@hotmail.com Recibido 15/10/2020. Aceptado 19/05/2021
} 
space to get away from the vertigo, hustle and bustle and the obligations that transform the person into a prisoner of their own mandates and the implicit demands of the neoliberal system.

Keywords: positive violence, neoliberal imperative of performance, freedom, self-demand

\section{Breves consideraciones teóricas sobre violencia}

La violencia es definida como el uso de la fuerza para conseguir un fin, especialmente para dominar a alguien o imponer algo. Hannah Arendt, en Sobre la violencia (2005), profundiza esta definición, ya que distingue en la violencia un carácter instrumental, le da la condición de herramienta y, por ello, se utiliza para multiplicar la potencia natural. Arendt plantea que el poder, la autoridad, la fuerza y la violencia son los medios utilizados por el hombre para dominar al hombre, sin embargo, destaca que no son lo mismo: cada uno de estos instrumentos tiene características propias (una de las diferencias entre poder y violencia es que el poder necesita el número de personas que lo legitimen, mientras que la violencia, hasta cierto punto, puede prescindir de ese número porque descansa en sus medios) para someter al ser humano, ya que hay en él un instinto innato de dominación y una innata agresividad. Por lo tanto, es posible considerar la violencia como dispositivo que permite al individuo saciar su sed de dominación sobre otro individuo para subyugarlo a las propias disposiciones. Aunque son distintos fenómenos, poder y violencia aparecen juntos. La ecuación entre la violencia y el poder se basa en la concepción del Estado como dominio de un hombre sobre otros hombres a través de la violencia.

Por su parte, Bauman en Daños colaterales. Desigualdades sociales en la era global (2011) sostiene que el Estado contemporáneo descansa su legitimidad en la cuestión de la seguridad personal, es decir, el ciudadano debe protegerse por sus propios medios de los peligros advertidos constantemente por los medios de comunicación, donde la inseguridad y la incertidumbre la provocan los extraños, los inmigrantes, el "otro" que no cumple con cierto tipo de requisitos. En este sentido, Bauman destaca que la violencia del Estado descansa en el racismo, en la marginación del hombre por el simple hecho de ser diferente (2011). A su vez, los extraños se convierten en el chivo expiatorio de las políticas gubernamentales para sostener su poder e influencia. Así, el "otro" es deshumanizado y se convierte en objeto de la ley y el orden, como así también en justificación de la violencia ejercida sobre esa persona que se considera ajena.

Por otra parte, en la actualidad, de acuerdo con la propuesta del filósofo coreano ByungChul Han, la violencia deja de ser visible para convertirse en algo invisible, "de frontal en viral, de directa en mediada, de real en virtual, de física en psíquica, de negativa en positiva" (Han, 2013, p. 10). La violencia se vuelve anónima. En consonancia con lo expuesto por Zygmunt Bauman (2011), Han (2013) sostiene que la sociedad actual evita cada vez más la negatividad del otro. Se intenta suprimir, por lo tanto, la violencia de la negatividad, lo que no quiere decir que ésta desaparece, sino que se hace presente la violencia de la positividad, igualmente nociva debido a que la masificación de lo positivo trae aparejados excesos: la sobreproducción, la hipercomunicación y la hiperactividad. De esta manera, la violencia positiva no es externa, no es perceptible, sino que es interna (se vuelve más difícil de distinguir). La presión pasa al interior, a la psicología del individuo, quien se autolesiona o ejerce violencia sobre sí mismo por la necesidad de cumplir con las exigencias autoimpuestas a partir de una sociedad obsesionada con el rendimiento y la producción continua. 


\section{La violencia positiva representada en La habitación oscura}

A su vez, Isaac Rosa, escritor español nacido en Sevilla en 1974, demuestra, a lo largo de todas sus obras, un marcado compromiso con la realidad. En toda su literatura se preocupa por indagar sobre qué nos pasa como sociedad. Se siente parte de la comunidad y se acerca a los grupos menos favorecidos, que, en su mayoría, no son representados o son olvidados por los novelistas. Rosa ${ }^{1}$ toma la responsabilidad de poner en foco los problemas que no se cuentan y que son dejados de lado por el discurso dominante.

En La habitación oscura ${ }^{2}$ (2013) lleva a cabo una mirada generacional al tiempo presente. Se realiza el retrato de una generación, víctima ante la crisis actual. La estructura, en este caso, es circular, ya que la historia arranca en el mismo punto del presente y los quince años que han transcurrido en la vida de los protagonistas (un grupo de adultos a los que los une el haber compartido en su juventud el sótano de un local alquilado para tener relaciones sexuales) se reconstruyen a modo de analepsis y prolepsis. Así, el retorno al pasado sirve para explicar la situación actual, los pensamientos, sentimientos y conductas de quienes esperan en una habitación oscura a que la policía venga a detenerlos. Habitación que en el principio sirvió para escapar de la realidad y dejarse llevar por el placer. Aquí, Isaac Rosa, de acuerdo con José Jurado Morales (2014), destaca el derrumbe del mundo capitalista por culpa de una crisis grupal que empieza y termina en el ámbito moral y que se presenta desde la óptica económica y financiera. Invita al lector a pensar la crisis como un fracaso colectivo, de toda la sociedad y no sólo por la inoperancia de los gobernantes.

A su vez, Rosa hace uso en La habitación oscura de la teoría de pensadores como Zygmunt Bauman y Byung-Chul Han para destacar el frenético ritmo de vida al que el hombre está sometido, no sólo por la sociedad capitalista y consumista, sino también por la autoexigencia que ejercen sobre sí mismos los protagonistas para mantener sus estatus, sus privilegios y sus beneficios. Como se dijo anteriormente, mediante un juego de analepsis y prolepsis, pone en evidencia la primera crisis económica del tercer milenio. Igualmente, no solo analiza la ruptura del orden económico mundial, sino también la decadencia de un grupo de personajes que experimentan momentos de felicidad y de pesar a lo largo de quince años. La soltura, el desparpajo, el ímpetu mutan hacia ataques de pánico y temor a ser apresados por terrorismo cibernético ${ }^{3}$. Para visibilizar la involución de los personajes, el relato comienza por el final, en el que los protagonistas, encerrados en un cuarto oscuro, comienzan a recordar que, en un principio, ese habitáculo fue refugio de cada uno de los personajes:

Gira la habitación, el planeta entero invirtiendo su deriva para que borremos la firma de contratos de trabajo, hipotecas y libros de familia... para que devolvamos a las fábricas y a la tierra todo lo consumido... anulemos decisiones y revirtamos rupturas y solo así, rehaciendo todo ese camino de regreso, seríamos capaces de ser otra vez aquellos que un día quedaron a oscuras por primera vez. Nosotros, los de entonces. (Rosa, 2013, p. 16)

Con esta pequeña mención a un conocido poema de Neruda y retomado por Jaime Gil de Biedma en "Elegía y recuerdo de la canción francesa", el narrador, que alterna la persona desde la que relata (la primera del plural y la segunda y tercera de singular), hace una breve enumeración de lo ocurrido hasta la noche en que se reencuentran todos y esperan, con temor e incertidumbre, las represalias por haber querido luchar contra el sistema.

El imperativo neoliberal de rendimiento estudiado por Byung-Chul Han en Topología de la violencia (2013) y La expulsión de lo distinto (2016) presenta a la sociedad actual como una sociedad de la autoexplotación. Aquí, el sujeto se explota hasta quedar abrasado: síndrome de burnout. Se desarrolla, por lo tanto, una autoagresividad, que en muchas 
oportunidades finaliza con el suicidio del individuo. Vemos, de este modo, que surge una coacción interna y no solo externa únicamente.

En La habitación oscura, la violencia que los protagonistas ejercen sobre su persona se presenta al lector mediante la utilización de un vocabulario propio de la cinematografía como el time-lapse. A partir de esta técnica propia del cine, las enumeraciones ascendentes se aceleran progresivamente:

Hoy la memoria tiene prisa... así que toma todos los capítulos, todas las temporadas de la telecomedia y las pasa a cámara rápida, muy rápida, hasta quedarse con un puñado de fotogramas por episodios que, acelerados, logran ese efecto que llaman time-lapse... nuestra independencia exigió cientos de firmas, montañas de documentos y anexos y pliegos y condiciones generales y cláusulas y letras pequeñas y fotocopias que llenaron archivadores y que todavía conservan en cajas precintadas en los trasteros... hay otros planes de sábado, hay teatros, hay conciertos, hay restaurantes recomendados, hay aviones baratos que a la velocidad de la luz conducen a capitales europeas, hay hoteles con encanto, son años en que nuestras cuentas bancarias se mueven a la misma velocidad que esta película que proyectamos a ritmo enloquecido: ingresos y gastos, nóminas abonadas a principio de mes de cuyo importe vemos descontar números como un reloj en cuenta atrás disparada... en el cajero han acelerado la marcha atrás de la cuenta... y que al desaparecer por nuestras narices imponen un ritmo todavía mayor a la película, nos hacen correr más deprisa... mientras seguimos vaciando cajas de mudanza, emparejándonos y desemparejándonos... al tiempo que como hormigas esforzadas corremos siguiendo hiladas para encontrar tallos, restos orgánicos, pequeñas carroñas, la ciudad cruzada por miles de regueros de quienes transportamos alimentos, podríamos ver nuestro trabajo de aquellos años a la misma velocidad, girando aún más la manivela para ver cómo se acumula lo consumido. (Rosa, 2013, pp. 44-48).

En este ejemplo, el vértigo de los acontecimientos se hace más evidente porque el relato carece de división en párrafos, el lector siente la opresión de esos años de hiperproducción al no poder hacer un descanso durante la lectura. La descripción de los hechos pone evidencia la velocidad que los protagonistas se imponen para formar parte del sistema y mantenerse en lugares de privilegio. La vida se vuelve una apariencia que demanda una búsqueda constante de ascensión de estatus.

A su vez, la animalización de los personajes, fruto de la influencia valleinclaniana - como así también de Camilo José Cela, Carmen Laforet, entre otros - sirve para hacer evidente la deshumanización del hombre; el individuo pierde entidad y se convierte en un autómata sin capacidad para el raciocinio.

La habitación oscura se vuelve, para los protagonistas (de los cuales solo algunos están nominados ${ }^{4}$, como María, Raúl, Sergio, Olga, Silvia, etcétera, recién a partir de la página 53) un lugar imprescindible, forma parte del camino vital de los personajes, ya que se convirtió en el lugar donde todos podían tomar aire, escapar del tedio, la rutina y la carrera mortal por seguir estables económicamente. Se convierte en el sitio al cual acudir cuando todo se derrumba:

Tal vez ese pie que muchas noches pisó y del que se apartó era de Lola... Su derrumbe fue otro, ella no tenía una habitación infantil, aunque también miraba desde la puerta el interior de un dormitorio: aquel en el que dormía su 
padre, cuyo sueño ruidoso espiaba mientras fantaseaba con colocarle una almohada sobre la cara. Y aunque alguna noche llegó a apretar entre las manos un cojín, siempre acababa saliendo a la calle y acudiendo a la habitación oscura, donde creía desprenderse del olor a viejo que le dejaba su padre. (Rosa, 2013, p. 85)

En esta cita podemos ver ya el agotamiento de uno de los miembros del cuarto compartido que utilizaban, en un principio, para satisfacer apetitos sexuales sin la obligación de entablar un compromiso. Las obligaciones de Lola ya pesan en su cuerpo y en su mente. Debe vivir y cuidar a su padre porque los tiempos de bienaventuranza se vuelven escasos paulatinamente. Sin embargo, es necesario tener en cuenta que el sujeto de rendimiento del que Han habla no trabaja por obligación.

\section{¿Libertad o promesa de libertad?}

En la posmodernidad nace una paradoja donde la libertad, el placer y el entretenimiento tienen un lugar sumamente importante. El individuo obedece a sí mismo, por lo que es, a la vez, amo y esclavo de sí mismo. El ser humano, por lo tanto, se auto explota creyendo que se está realizando. Byung-Chul Han declara que tras el espejismo de la libertad se esconde el dominio neoliberal. El dominio se consuma en el momento en que coincide con la libertad (Han, 2016). Libertad trágica porque imposibilita la resistencia.

Equiparando las vicisitudes de los protagonistas con una telecomedia, Rosa muestra los altibajos de este grupo de personajes:

Cada uno aceptó el personaje que le había tocado en el reparto... así éramos y así nos comportábamos, siguiendo una trama de altibajos pero con promesa de final feliz, donde lo fundamental eran las preocupaciones sentimentales... y si había otras preocupaciones, si había momentos de fatiga, de pérdida, de fracaso, de miedo, de humillación, esos momentos funcionaban como los contrapuntos necesarios en toda buena historia... El dinero, por ejemplo, era central, ahora lo entendemos así, pero entonces no lo veíamos, no lo nombrábamos, porque era natural, era el aire que respirábamos. Sin él, nos asfixiábamos, claro, pero fueron años de buena ventilación... cada uno tuvo su afán en aquellos años, cada uno dibujó su mapa del tesoro, su cuento de la lechera porque parecía fácil, porque nos lo habían prometido, porque habíamos nacido para eso. (Rosa, 2013, p. 52).

En las últimas palabras de este fragmento es posible distinguir la ironía presente en el relato (una de las estrategias discursivas predilectas de Isaac Rosa) para señalar que el orden neoliberal le otorga libertad al hombre y lo convence de que merece beneficios mayores mientras más se esfuerce. El ser humano lucha y compite contra sí mismo en una batalla cuya definición siempre será perjudicial para la salud de ese mismo ser humano. La ilusión de los protagonistas por lo prometido se relaciona estrechamente con Foucault y su Microfísica del poder, analizada en profundidad por Byung-Chul Han en el sentido de que los procesos de poder tienen la función de calificar, medir, apreciar y jerarquizar. Se trata, entonces, de un poder normalizador y silente que ejerce una violencia invisible sobre el sujeto, que se flagela para estar a la altura de la norma. Así, la psiquis del individuo se define por el poder y no por el deber. En palabras de Byung-Chul Han, "el imperativo del rendimiento transforma la libertad en una coacción” (Han, 2013, p. 75). Aparece la autoexplotación en lugar de la 
utilización ajena. La persona se explota a sí misma hasta desmoronarse. De este modo, la violencia y la libertad se necesitan mutuamente.

\section{Desenlaces funestos del imperativo de rendimiento}

Uno de los personajes escasamente mencionado es Eva. Adquiere relevancia cuando se habla de su intento de suicidio y la concreción de este:

Es la única que con toda seguridad hoy no está aquí, sentada en este círculo mudo: Eva. No supimos por qué había hecho aquello, no hubo tiempo para saberlo: el hospital no era lugar para preguntas, solo para animarla cuando su familia nos permitió visitarla y la encontramos en un sillón, demacrada y consumida bajo el camisón, la mirada en la ventana. Tampoco hubo tiempo para hablar después, cuando le dieron el alta en la unidad de psiquiatría... ella prefirió tomar un atajo: al entrar en el piso, su hermano llevó la maleta... le preguntó a voces si quería darse una ducha antes de comer, volvió al salón al no escuchar su respuesta, encontró la chaqueta de ella tirada en el suelo, el bolso un par de metros allá, junto al balcón abierto, al que no tuvo valor de asomarse para comprobar por qué gritaba de esa manera la gente en la calle. (Rosa, 2013, p. 126).

El tipo de muerte que Eva eligió es significativo: decidió volar, escapar del orden interior que la torturaba y deprimía. La depresión, junto con el burnout (síndrome provocado por horarios de trabajo excesivos, realización de tareas que no corresponden con el puesto de trabajo y la redistribución insuficiente del dinero que traen aparejado un agotamiento físico y mental, con falta de motivación absoluta), también llamado síndrome del trabajador quemado, presentan características de la autoagresión. La libertad normalizada hace que el ser humano se lance eufórico a trabajar hasta que culmina con su derrumbe. El individuo se mata en el intento por realizarse. Si bien Eva es la única de los protagonistas cuya depresión es letal, los demás personajes experimentan picos de estrés, ataques de pánico por el exceso de obligaciones que perjudican a todos:

Pese a la ligereza con que parecíamos cubrir etapas como transportados en una cinta mecánica, había momentos en que el juego de contrapesos temblaba, el chasquido se volvía zumbido persistente, una pinza cerrada en el pecho, una noche sin dormir y ansiedad y miedo y la vida era esto y el cansancio de lo mucho que todavía había que pedalear y levantarse una y otra vez y no llorar y seguir subiendo y empujar y no caer al ser empujado y los lunes y los hijos y las recompensas efímeras y la fantasía de dejarlo todo. (Rosa, 2013, p. 81).

Para contrarrestar los síntomas del estrés extremo, algunos personajes acuden a tranquilizantes, somníferos, anfetaminas, cocaína, entre otros estupefacientes, por lo que el hombre cae en un círculo vicioso del que no hay escapatoria. La presión interna, vemos, desarrolla rasgos autoagresivos. La expulsión de lo distinto, la desaparición de la violencia hacia el "otro" crea un proceso de autodestrucción, por lo que la producción se vuelve destructora porque el imperativo neoliberal de rendimiento reduce el cuerpo a un objeto funcional que hay que optimizar, objeto que se impone cada vez más fechas límite, más metas inalcanzables, etcétera.

En esta competencia nociva para sí mismo, el miedo ejerce un papel fundamental, ya que es él el que obliga al hombre a producir continuamente por temor a que los logros obtenidos 
se pierdan y la vida alcanzada se destruya. Nacen miedos como el pánico a ser marginado ${ }^{5}$, miedo a equivocarse, temor a fallar, miedo a fracasar, pavor a no responder a las exigencias propias, que se intensifican por la constante comparación con los demás. De acuerdo con Byung-Chul Han, la lógica del neoliberalismo se rige por la convicción de que el miedo incrementa la producción. El neoliberalismo, entonces, se vale del horror para perpetuarse y destruir poco a poco la fortaleza del ser humano hasta el punto de la autoalienación. Al sentirse el individuo presionado por aportar rendimiento, se autopercibe como un objeto utilitario que hay que perfeccionar, por lo que se va alienando gradualmente de él mismo. El desalentador resultado de esta alienación es la derivación en la percepción psicológica del organismo, donde finalmente el sujeto ya no siente su propio cuerpo, deja de tener control sobre él. Por lo tanto, no pierde solo su identidad, sino también su autonomía:

Pablo acababa de entrar, no llevaría ni cinco minutos sentado en un lateral cuando sintió el pinchazo... Llevaba ya semanas con repentinas aceleraciones cardiacas y una leve presión en el pecho que aunque permanente no llegaba a preocuparle, lo achacaba a los nervios. Pero ahora el dolor ya cruzaba el tronco entero y se irradiaba hacia los brazos. Le costaba respirar, intentó una bocanada amplia, sin éxito: el aire no se abría paso a los pulmones, que parecían no tener espacio suficiente en la dilatación del pecho... Le sudaba la espalda pegada a las planchas acústicas, estiró los brazos para forzar la entrada de aire pero algo le aplastaba las costillas... Me muero, pensó. Me muero, pero aquí no, aquí no... La angustia le impedía orientarse, no recordaba en qué dirección se había desplazado al entrar esa noche. Ahora sí logró expulsar una bocanada de aire, que repuso en una inhalación profunda, pero parecía que el aire contribuía a colmatar aún más el pecho... Se vio a sí mismo muerto, caído sin conocimiento al suelo y convulsionando a oscuras hasta que el músculo cardiaco se detuviese. (Rosa, 2013, pp. 87-88).

Los síntomas que experimenta Pablo son los de un ataque de pánico y, a la vez, son una analogía de la falta de verdadera libertad que el hombre necesita. Pablo necesita respirar, descansar, como así también expulsar temores y recibir amor, no terminar como un cadáver abandonado en el sótano de un local de usos múltiples. Finalmente, aunque con cierta resistencia, recibe la ayuda de Andrés quien se encontraba en la habitación oscura para liberar la carga que lo aqueja. Al presentar lo ocurrido a Pablo, Rosa advierte y llama a la reflexión sobre lo nocivos que pueden ser los mandatos autoimpuestos: pueden provocar que el cuerpo termine exhausto y deje de funcionar.

\section{La oscuridad como salvación}

Por otra parte, Isaac Rosa invierte el sentido negativo de la oscuridad porque es la habitación oscura donde acuden los protagonistas cuando la inescrupulosa sociedad de rendimiento los destruye (como ocurre con Lola, Andrés, Pablo, María, entre otros). Allí, la oscuridad, acompañada por el silencio y la sensación de que el tiempo se detiene sirven, al inicio, para la experimentación sexual, pero luego cumple el rol de sitio para huir de la insoportable realidad. Es necesario tener en cuenta que la novela puede dividirse en dos partes: la primera, que se extiende desde el primer capítulo hasta el final del tercero y la segunda, del cuarto capítulo hasta el final. En este artículo nos centramos en la primera parte por considerar que es allí donde se hace más patente la descripción del flagelo de los protagonistas, mientras que en la segunda parte la atención se vuelve sobre los mecanismos de control cibernético. Por lo tanto, la habitación oscura como refugio para escapar del tedio 
insoportable es más evidente en la primera parte, más allá de que en la segunda parte los protagonistas esperen a ser apresados en el mismo lugar de siempre.

Asimismo, Isaac Rosa emplea una serie de binomios para destacar que no todo lo que se piensa que es perjudicial ni todo lo que se cree beneficioso es sano para el hombre: claridadoscuridad, ruido-silencio y celeridad del tiempo-dilación del tiempo. En la novela, el cuarto a oscuras suple la carencia de afecto por una mano amiga desconocida. Este lugar posibilita la quietud del pensamiento y el reencuentro con el propio cuerpo a partir del tacto con el otro:

Podríamos levantarnos uno tras otro y situarnos en el centro del círculo para contar cómo recordábamos aquellas tardes en que embocamos la oscuridad como un aire más limpio, aquellas noches en que dormimos aquí sin saber que no estábamos solos, o quizás sabiéndolo, sintiendo la respiración de los durmientes como parte de esa protección... solo aquí dejábamos de oír el crujido insoportable. (Rosa, 2013, p. 90).

Jurado Morales (2014), por su parte, sostiene que la entrada en la habitación implica el acceso a un estado de placer sexual, como así también quietud y paz motivadas por la ruptura espacio- temporal que exige la rutina y por la aceptación de una lógica del silencio y la oscuridad. El cuarto oscuro simboliza el espacio vacío donde el ser humano puede dejar de lado todas sus preocupaciones, obligaciones, carreras imposibles de ganar. Representa ese vientre materno al que los protagonistas desean regresar porque en él solo impera la calma, la armonía y la autenticidad. Sin embargo, es preciso tener en cuenta que, en el final de la novela, los protagonistas usan la habitación oscura como refugio que está pronto a ser descubierto, con el consiguiente apresamiento de todos los reunidos allí. Por lo tanto, podríamos establecer que la oscuridad es salvadora $\mathrm{y}$, a la vez, la que imposibilita ver la gradual decadencia de la sociedad actual. Solo en el racconto de lo sucedido a lo largo de quince años, los personajes caen en la cuenta de que fueron animales, androides que trabajaron incansablemente para mantener un equilibrio que nunca fue tal y que los sumió en enfermedades, tristeza, desasosiego e incertidumbre ante la vida. La oscuridad obstaculizó caer en la cuenta de lo difícil que es vivir, madurar y tener cada vez más responsabilidades.

\section{Conclusiones}

Rosa, en la primera parte de La habitación oscura, denuncia las consecuencias de la violencia positiva propuesta por el imperativo neoliberal de rendimiento a partir del relato circular de un grupo de amigos que experimentan, a lo largo de quince años, el auge y la decadencia no solo de sus vidas, sino también de la crisis del sistema económico mundial.

Gracias a la utilización de analepsis y prolepsis, el lector reflexiona sobre la inclemencia del nuevo orden mundial que promete la ilusión de libertad al ciudadano, cuando en realidad esa independencia aparente lo trasfigura en prisionero de sus propias exigencias. El lector puede, a su vez, meditar sobre la autoexplotación a la que se somete el ser humano para alcanzar el nivel de vida que el sistema neoliberal propone como ideal y que resulta inalcanzable.

Asimismo, Rosa introduce un sitio, un lugar donde los protagonistas pueden gozar, disfrutar del silencio, sentir que el ritmo vertiginoso de la vida se detiene y dejan de ser autómatas para recuperar su esencia, su identidad y su intimidad.

A partir de la tríada oscuridad, silencio y tiempo, los personajes pueden evadirse del tedio de la rutina y la celeridad de la vida contemporánea en los capítulos uno, dos y tres, mientras que en la segunda parte (que se extiende desde el capítulo cuatro hasta el final) la habitación 
oscura cumple la función de refugio de los protagonistas que esperan atemorizados por la posibilidad de ser castigados por crímenes cibernéticos.

Rosa expone la pérdida de libertad del sujeto no solo por el imperativo neoliberal de rendimiento, sino también la pérdida de libertad a manos de la vigilancia y el control cibernético y propone una habitación oscura como espacio simbólico en el que recuperar el anonimato y la identidad propia, lograr una fuga individual y un reencuentro con la intimidad y el propio ser. Pone de manifiesto la necesidad de volver a una etapa donde el vértigo por lograr lo inalcanzable desaparezca.

\section{Referencias bibliográficas}

Arendt, H. (2005). Sobre la violencia. Madrid: Alianza.

Bauman, Z. (2011). Daños colaterales. Desigualdades sociales en la era global. Buenos Aires: Fondo de Cultura Económica.

Genette, G. (1972). Discurso del relato: Ensayo de método. Figuras III. Ed du Seuil, Coll. Poétique.

Gullón, G. (2006). Novelistas nacidos en los 60 y 70. Alicante: Biblioteca Virtual Miguel de Cervantes.

Hamon, P. (1977). Para un estatuto sociológico del personaje. En R. Barthes, W. Kayser, W. C. Booth y P. Hamon (Cols.), Poétique du récit (pp. 115-129). París: Seuil.

Han, B. C. (2013). Topología de la violencia. Recuperado de https://www.libronube.com/descargar-topologia-de-la-violencia-byung-chulhan/29854/

Han, B. C. (2016). La expulsión de lo distinto. Recuperado de https://www.libronube.com/descargar-la-expulsion-de-lo-distinto-byung-chulhan/40365/

Jurado Morales, J. (2014). La literatura como responsabilidad social: La habitación oscura de Isaac Rosa. Ínsula, 69(809), 34 a 37.

Rosa, I. (2013). La habitación oscura. Barcelona: Seix Barral.

\section{Notas}

${ }^{1}$ Es preciso tener en cuenta que, al haber nacido en la década de los setenta, Rosa forma parte de los escritores transmodernos (Gullón, 2006) — denominación que ni él ni los demás miembros de su generación aceptan y adoptan-, cuyos libros se caracterizan por el eclecticismo y la posmodernidad. Es necesario tener en cuenta que los escritores transmodernos hacen uso de recursos de otros géneros para estructurar sus obras. A su vez, la narrativa más reciente muestra fuerte presencia en el texto del archivo, del documento bajo formas diversas (reproducción facsímil, fotos.) y mediante distintas modalidades (inserción, cita, intertextualidad, entre las más utilizadas.). El ensayo, el columnismo y el testimonio cumplen un papel estructurador y hacen que la hibridez sea un rasgo destacado de la literatura española actual. Se asume, además, el marco del género policíaco como sistema de búsqueda. Toman, también de este género la unión del neorrealismo subjetivista, la intriga y la crítica social. Asimismo, la narrativa de las últimas décadas se aleja del canon aristotélico y renuncia a una lógica cronológica y causal. Se cultiva la horizontalidad, la simultaneidad, la discontinuidad, la multiplicidad junto con el fragmentarismo; todo ello producto de haber crecido en una época donde el zapping televisivo y las plataformas de la red significan otra forma de conocimiento e investigación. También, la escasez en la caracterización de los personajes y su profundización es común en los escritores de esta época (Champeau, 2011).

${ }^{2}$ Rosa, Isaac (2013). La habitación oscura. Seix Barral, Barcelona. Es necesario aclarar que las citas que utilizaremos de aquí en adelante provendrán de esta edición.

${ }^{3}$ Es preciso puntualizar que la novela La habitación oscura puede dividirse en dos partes: la primera que se extiende desde el primer capítulo hasta el final del tercero y la segunda, del cuarto capítulo hasta el final. En este artículo nos centraremos en la primera parte por considerar que es allí donde se hace más patente la descripción del flagelo de los protagonistas, mientras que en la segunda parte la atención se vuelve sobre los mecanismos de control cibernético. 


\footnotetext{
${ }^{4}$ De acuerdo con Phillippe Hamon (1977), el personaje de novela se construye progresivamente mediante notaciones figurativas consecutivas y difusas a lo largo del texto, que no despliega su figura completa hasta el final de la obra. Por lo tanto, conoceremos a fondo al personaje una vez que hayamos leído todo el libro. Teniendo en cuenta que Hamon piensa al personaje como un morfema doblemente articulado por un significante discontinuo (una cierta cantidad de marcas) que remite a un significado discontinuo (el "sentido" del personaje), en La habitación oscura, la cantidad de marcas del significante es económica porque sólo se precisan los nombres de los personajes o ni siquiera eso. Tampoco conocemos el oficio de ninguno, a excepción de Jesús, que sabemos que trabaja en Ingeniería de Sistemas o algo similar. Si bien conocemos que transcurren quince años de vida de los protagonistas no sabemos a ciencia cierta sus edades, no se precisa ni la década de vida por la que transitan. Es decir que, en la novela el "ser" de los personajes tiene menos incidencia que el "hacer" de estos. Conocemos a los personajes por sus acciones y actitudes más que por sus características identitarias.

${ }^{5}$ En este sentido, la obra guarda relación con otra novela de Rosa, El país del miedo (2008) donde uno de los incontables temores que el protagonista experimenta es el miedo a perder todo y ser excluido, no quiere convertirse en uno más ni quedarse fuera del sistema. La habitación oscura pule determinadas ideas y tópicos que se tratan en El país del miedo y Rosa se perfecciona en la utilización de estrategias discursivas de diversa índole.
} 